\title{
Retraction Note to: Atmospheric characteristics of coastline based on remote sensing images and tourism brand construction in coastal
} areas

\section{Xiangxiang Xie ${ }^{1}$}

Published online: 7 December 2021

(c) Saudi Society for Geosciences 2021

Retraction Note to: Arabian Journal of Geosciences (2021) 14: 588 https://doi.org/10.1007/s12517-021-06943-5

The Editor-in-Chief and the Publisher have retracted this article because the content of this article is nonsensical. The peer review process was not carried out in accordance with the Publisher's peer review policy. The Publisher has not been able to obtain a current email address for the author.

The original article can be found online at https://doi.org/10.1007/ s12517-021-06943-5.

Xiangxiang Xie

xiexiangxiang@hainanu.edu.cn

1 Tourism College of Hainan University, Haikou, Hainan,

China 